Article

\title{
Advanced Manufacturing Technologies and Green Innovation: The Role of Internal Environmental Collaboration
}

\author{
Ting Kong ${ }^{1}$, Taiwen Feng ${ }^{2, *}$ and Chunming Ye ${ }^{1}$ \\ 1 Business School, University of Shanghai for Science and Technology, Shanghai 200093, China; \\ kongting@usst.edu.cn (T.K.); yechm@usst.edu.cn (C.Y.) \\ 2 School of Management, Northwestern Polytechnical University, Xi'an 710072, China \\ * Correspondence: typhoonfeng@gmail.com \\ Academic Editor: Bart A.G. Bossink \\ Received: 16 August 2016; Accepted: 14 October 2016; Published: 21 October 2016
}

\begin{abstract}
Green innovation has been deemed a key corporate capability to deal with environmental issues. The usage of advanced manufacturing technologies (AMT) provides important resources and knowledge for firms' green innovation. Drawing on a resources-based approach, this study contributes to the existing literature by examining how the adoption of specific types of AMT (process, design, and planning) influences two dimensions of green innovation (green product innovation and green process innovation). In particular, we explore these relationships through internal environmental collaboration. Based on data collected from 198 Chinese manufacturing firms, we found that process, design, and planning AMT can contribute to both green products and process innovation. Moreover, the findings confirm the significant mediating role of internal environmental collaboration in this relationship. Specifically, internal environmental collaboration mediates the relationship between process AMT and green product innovation as well as the relationship between design AMT and two dimensions of green innovation; it also partially mediates the relationship between process AMT and green process innovation as well as the relationship between planning AMT and two dimensions of green innovation. These findings provide novel insights into how manufacturing firms can use various types of AMT to enhance their green innovation.
\end{abstract}

Keywords: AMT; green innovation; internal environmental collaboration; mediating effect

\section{Introduction}

Facing increasing environmental pressure, green innovation has become increasingly important for manufacturers to achieve sustainable development. A great number of well-known economists have called for policies to encourage both public and private investment in the development of technologies and practices to enhance green innovation. Strict environmental regulations and the popularity of environmentalism have changed the competitive rules and patterns for firms [1] and make green management profitable nowadays [2]. Given this context, manufacturing firms have increased their green innovation initiatives and have been integrating green innovation into their core business strategies. However, green innovation research is still in its early phases and how to enhance green innovation is a scarcely understood phenomenon [3].

The quest for improved overall effectiveness in manufacturing has forced a large number of firms to invest in advanced manufacturing technologies (AMT) [4]. Prior studies have argued that the adoption and use of AMT are associated with a wide range of benefits, including improvements in market share and profitability [5,6], improving flexibility, delivery, cost reduction, and quality $[4,5,7]$, enhancing manufacturing productivity and efficiency $[7,8]$, as well as fostering firms' competitive advantages and manufacturing performance [4,9-11]. In recent decades, researchers also contended 
that AMT in the design, planning, and manufacturing process can be deemed as potential sources for innovation [12,13]. The use of AMT provides opportunities to ensure proper product utilization [14,15], apply pollution control and pollution prevention technologies $[13,16]$, share management techniques and knowledge among various functions [8], establish dynamic capability to offset uncertainty and shorten the life cycle of products [17], and enhance competitive advantages and innovation performance [4,12].

Although AMT adoption has been identified as a key driver of innovation in the literature, the empirical evidence of its benefits on green innovation has been surprisingly limited. Company managers are interested in knowing what the key drivers are in establishing green innovation practices [18]. Incomplete understanding of the potential benefits of AMT on green innovation may hamper the development of a widely accepted framework that would characterize and categorize green innovation activities in manufacturing firms. Therefore, it is important to acquire a holistic view to investigate whether and how AMT adoption affects green innovation. In this study, we attempt to fill this research gap by focusing on the potential antecedents of green innovation, specifically the adoption of AMT. In addition, in order to fully understand AMT and its relationship to green innovation, there is a need to examine how individual types of AMT are related to different dimensions of green innovation. Through empirically examining the relationships between the use of process, design, and planning AMT and both green product and green process innovation, this study extends prior research by developing a theoretical basis and providing empirical evidence for the relationship between AMT adoption and green innovation from a multidimensional perspective.

Furthermore, previous studies emphasize that the link between implementation of AMT and green innovation may not be direct [15,19]. This calls for exploring the issues of how AMT adoption exactly influences green innovation. Against the foregoing backdrop, we argue that whereas AMT has a potential value for green innovation, the actual impact is achieved when experts, analysts, and decision makers can detect and assimilate technological knowledge within the firm. Because technological knowledge is tacit in nature, information sharing across various departments reflects a key competitive capability for successful knowledge assimilation and green innovation achievement $[20,21]$. Therefore, we propose a critical organizational capability, internal environmental collaboration, as a mediator through which effective AMT adoption can ultimately lead to green innovation. Employing a mediation approach offers the benefits of a more comprehensive understanding of the mechanism underlying the AMT-green innovation relationship.

Our research contributes to the AMT and green innovation literature in several ways. First, this study adds to the literature by incorporating AMT as an antecedent of green innovation and empirically examining the relationship between them at dimension levels. Second, this study develops a more comprehensive theoretical model of how firms' green innovation benefit from the uses of AMT through the critical mediator of internal environmental collaboration. Third, this study extends green innovation research in the context of an emerging economy. Our findings will inform Chinese managers how to deal with dilemmas in green innovation due to different AMT implementations.

The rest of the paper is organized as follows. In the second section, we discuss the theoretical underpinnings, develop a conceptual model, and present the research hypotheses. In the following two sections, we describe the research method and present the results of empirical analyses. The implications for research and practice are discussed in the fifth section. Finally, conclusions and opportunities for future research are presented in the sixth section.

\section{Theoretical Background and Research Hypotheses}

AMT is a multi-dimensional concept that focuses on technologies comprising the "factory automation" component of computer-integrated manufacturing $[4,7,22]$. To investigate the effective patterns of AMT adoption, we conceptualized three types of AMT including process AMT, design AMT, and planning (administrative) AMT, which are consistent with prior studies [7,23,24]. Process AMT refers to technologies that focus on controlling manufacturing processes and generating process related information on the factory floor, which involves computer-aided manufacturing (CAM), 
robotics, flexible manufacturing systems (FMS), and environmental control systems. Design AMT refers to technologies that focus primarily on product definition, design, and related information processing functions, which includes computer-aided process planning (CAPP), computer-aided design (CAD), computer-aided engineering (CAE), product data management (PDM), and rapid prototyping. Planning AMT, such as enterprise resource planning (ERP), manufacturing resource planning (MRP II), activity-based accounting, and decision support systems, refers to technologies that control and monitor the material flow from the acquisition of raw materials to the delivery of finished products as well as the technologies that manage the information flow and coordinated decision-making between functions. In these terms, the essential characteristic of AMT is its application of computers to manage data associated with manufacturing processes [19].

Green innovation can be defined as the creation or improvement of products or processes involved in energy saving, pollution-prevention, waste recycling, green product designs, or corporate environmental management that aims to prevent or reduce environmental impacts and contribute to environmental sustainability [25]. Green innovation is also a multi-dimensional construct and can be divided into two foremost dimensions: green product innovation and green process innovation $[25,26]$. Green product innovation refers to environmental product innovation that helps to reduce resource, control pollution, manage waste costs, and decrease the negative impact on the environment. Companies that pioneer green product innovations can improve their product design, quality, and reliability with respect to environmental concerns, which can yield a better chance to gain the "first mover advantage" and thus improve their corporate image, develop new markets, and further obtain competitive advantages [26]. Green process innovation refers to an improvement in the existing process and/or a generation of new processes that involve green manufacturing technologies or equipment to avoid or reduce environmental damage and lead to environmental improvements. Green process innovation not only prevents costly pollution, but also reduces resource expenses and overall costs [27]. Companies can undertake green process innovation to enhance resource productivity and manufacturing efficiency, thus obtaining cost advantages [26]. Both green product and process innovation can enhance the performance of environmental management and help businesses develop new market opportunities to increase competitive advantage [26].

The resource-based view (RBV) of a firm provides a suitable theoretical basis and perspectives to interpret the relationship between the use of AMT and green innovation. According to RBV, a firm's sustainable competitive advantage is determined not only by its unique resources but also by the capabilities to effectively exploit and combine resources in ways that are valuable, rare, inimitable, and non-substitutable [28]. AMT presents the important strategic resource (e.g., technological knowledge, expertise, and information) and an integral part of organizational capabilities that associated with green innovation activities. Since innovation performance is largely dependent on the assets or resources that firms own internally [29,30], the implementation of AMT provides critical resources and capabilities that enable a firm to respond to increasing environmental pressure by designing and producing green products and processes. As a result, AMT is vital for establishing and sustaining a defensible competitive advantage in green innovation.

Although the significant benefits of AMT are well recognized, the underlying mechanism through which it affects green innovation is still under-examined. To fill this gap, this study postulates that internal environmental collaboration mediates the influence of AMT adoption on green innovation. Internal environmental collaboration, which can be defined as the direct involvement of various functions within an organization in planning and developing jointly for environmental management and environmental solutions, represents the core competence of an organization that facilitates the identification and assimilation of technological knowledge to innovate environmentally. Valuable technological knowledge is often tacit, specialized, and socially embedded, which makes it difficult to transfer. Internal environmental collaboration provides direct and interactive access to various departments' know-how. Moreover, trust and commitment derived from internal environmental collaboration can enhance employees' motivations to share their proprietary technological knowledge, which increases the efficacy of knowledge transfer and 
assimilation to green innovation. As a consequence, internal environmental collaboration can act as a critical organizational capability that increases the probability of potential green innovation enhancements offered by AMT. Accordingly, we focus on internal environmental collaboration as the focal mediator between AMT adoption and green innovation. The conceptual model of this research is shown in Figure 1.

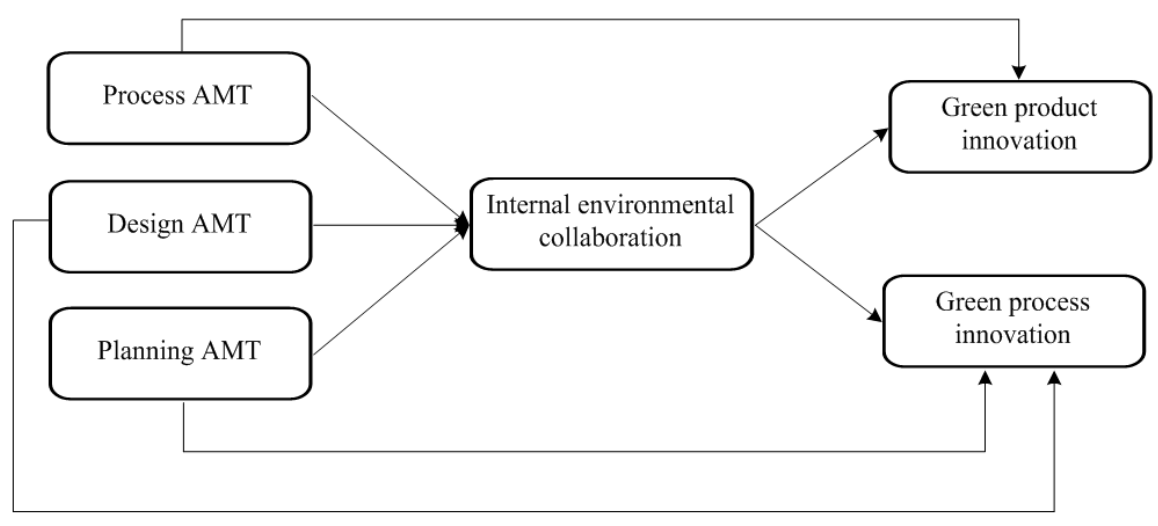

Figure 1. Conceptual model.

\subsection{AMT and Green Product Innovation}

An investment in AMT provides a strategic option that greatly expands the range of the firm's potential growth paths [8]. The AMT literature has long acknowledged the benefits of AMT implementation in manufacturing firms. Previous research supports the value of these practices in improvements in quality, flexibility, manufacturing productivity, efficiency, firms' competitive advantages, and manufacturing performance [4,19,31]. Moreover, implementing AMT may also help firms engage in higher value added activities, such as innovation [8]. AMT often marks a dramatic change from mechanized technologies to manual operations [32]. From initial AMT adoption, through system design and programming, to implementation and continuing improvement within the manufacturing plant, the use of AMT has a great impact on both green product and process innovation.

The use of AMT fosters green product innovation in two primary ways. Firstly, the use of process, design, and planning AMT helps to create new knowledge-based sources of advanced manufacturing competence that contribute to fostering green product innovations. The long-term implementation effectiveness of AMT largely depends on the richness of the firm's knowledge base [8]. The adoption and adaptation of AMT to particular circumstances usually involves generating, acquiring, assimilating, and recombining novel technological knowledge as well as transforming a general stock of knowledge into economically useful knowledge. This technological knowledge is generally intangible, such as understanding the state of technology, or know-how on adapting technologies developed by others [12]. Green innovation is extremely dependent on the availability of knowledge [33]. Therefore, the knowledge base created by AMT has to be recognized and managed to ensure successful green innovation.

Through structuring of the knowledge base, AMT provides the tools, processes, and platforms to ensure knowledge availability and accessibility. Both the development and dissemination of technological knowledge enhance the acceleration of sustainable manufacturing production $[34,35]$. For instance, the accumulation of technological knowledge and the improvement of product knowledge facilitate the recovery of a firm's end-of-life product and its recycling [36].

In addition, through provision of technological platforms and tools to enable knowledge sharing and interactive learning, AMT can facilitate collaboration as a mechanism to foster innovation [19]. To be specific, AMT implementation has a great potential to facilitate collaboration by improving cooperation between internal departments and among supply chain partners (suppliers and customers) [37]. The collaborative activities in regard to the environmental-related interactions 
and knowledge-sharing activities, such as meetings and workshops pertaining to green innovation, contribute to environmental technical development and product design and thus improve the chances of developing a green product.

Moreover, an extensive knowledge base also improves a firm's capability to combine previously unconnected knowledge in creative ways [38], which in turn has a great potential for enhancing green product innovation. Companies require the motivation and ability to produce creative and innovative ideas to develop new products [39]. The diversity of technological knowledge stimulates the firm to blend different knowledge elements, which represents a key cognitive process for generating innovative ideas [40], thus increasing the number and variety of potential combinations and novel solutions of new products [41]. For example, firms can combine existing and newly acquired environmental knowledge to develop green products that will be successfully promoted in the market [42].

Secondly, the use of process, design, and planning AMT has critical effects on improving efficiency and cost-saving with green product innovation. The utilization of AMT within a complex manufacturing system helps to increase the efficiency of the manufacturing system [4]; it can consequently be an important source of product innovation that leverages for environmental benefits relating to design and creativity [43]. More specifically, investment in green equipment and the installation of advanced green production technology can increase the resources' productivity to reduce environmental cost, thereby exerting a positive effect on green product innovation. In addition, companies' increased experience with AMT can stimulate proactive environmental actions like modification, redesign, and creation of new products and increase the cost-saving potential (e.g., energy or material saving), thus facilitating green product innovation. Examples include applying the environmental criteria and directives into the product modification through material substitution (e.g., water-based ink vs. oil-based ink).

Furthermore, the use of process, design, and planning AMT has a potentially positive effect on green product innovation. Green product innovation often incorporates the modification, redesign, and creation of new products that aim at green innovation, which are primarily related to technological changes in production processes [44]. Process AMT, which is considered a type of technology that supports the production and organizational process, has become an effective way of overcoming hurdles and generating a manufacturing process that reduces negative environmental impacts. In response to changes in technology and environmental regulations, process AMT can enhance green product innovation primarily through fostering efficiency improvements or changes in organization-wide processing solutions. Design AMT not only enables effective communication and collaboration on innovative product concepts and ideas, but also has integrated functionality enabling the calculation, storage, and manipulation of vital product information to provide better product quality and improved product features for environmentally conscious consumers. Planning AMT, which allows firms to manage material flow, can improve efficiency by optimizing production schedules to more fully utilize manufacturing resources [4]. Pollution is the concrete representation of the inefficient use of resources [1]. Manufacturing firms can increase resource productivity through planning AMT to enhance green product innovation and reduce the environmental costs. All of this points to the use of AMT being a critical factor to enhance green product innovation. Therefore, we propose the following hypotheses:

H1: The use of (a) process AMT; (b) design AMT; and (c) planning AMT is positively associated with green product innovation.

\subsection{AMT and Green Process Innovation}

In addition to green product innovation, the use of AMT also has a potentially positive effect on green process innovation. AMT enhances green process innovation mainly through increasing firms' information sharing and processing capabilities. Effective information sharing and processing is extremely important for the success of AMT implementation [20]. On the one hand, the use of AMT alter the way employees interact more efficiently and enables real-time information sharing 
within the organization, allowing direct access to product databases in a controlled manner. It has the potential to lead to deep communication and interaction across functional boundaries [45], which in turn results in improved cross-functional collaboration. The collaboration among different functional departments during the primary phases of new product or process development can improve innovation capabilities, thus fostering innovative performance [46]. Likewise, through exchanging quality eco-design information among various functions, the use of AMT could also contribute to green innovation. On the other hand, AMT's information processing capabilities enable employees to apply creative problem solving on the factory floor, resulting in improved products and processes $[47,48]$. Hence, the processing of green information and know-how guides green innovation activities. It is therefore important for manufacturing firms to employ AMT to be capable of green process innovation.

Moreover, the adoption of process, design, and planning AMT can enhance green process innovation. Manufacturing processes are often perceived as barriers to innovation because of the limitations in information flow [8]. Process AMT, which typically focuses on the production and delivery aspects of manufacturing [15], can be seen as the prerequisite for generating operational processes-related information. The implementation of process AMT helps enhance the integration of operational processes and information, which enables firms to reduce their negative environmental impact and direct the processing of materials, resources, and knowledge to a better performance of green process innovation. For example, process technologies like environmental control systems are likely to improve the information basis for green process innovation [49].

The use of design AMT also helps to improve green process innovation. Design technologies such as CAD and CAE closely link external suppliers, customers, and designers with manufacturers by using a common software interface and language that feed design data and customer specifications directly into the production system [24,50]. Customer expectations and supplier involvement are important factors that influence companies' environmental practices [18]. Therefore, using a common language has become a critical driver of green process engineering since it promotes the integration of design and manufacturing activities to pursue green process development opportunities.

Finally, the nature of Planning AMT suggests its benefits in green process innovation. By bringing automation and computational power together in coordinated decision-making, planning AMT such as ERP and MRP II help to optimize the utilization of resources to provide more efficient and environmental process plans that can meet the environmental regulations. Hence, we propose that the use of AMT can improve green process innovation, as illustrated in the following hypothesis:

H2: The use of (a) process AMT; (b) design AMT; and (c) planning AMT is positively associated with green process innovation.

\subsection{The Mediating Effect of Internal Environmental Collaboration}

Whereas the uses of process, design, and planning AMT are likely to stimulate a firm's green innovation, little is known about the underlying mechanism linking AMT adoption and green innovation. Internal environmental collaboration can be considered a unique organizational capability from the RBV logic [51], which can be expected to translate AMT into improved green innovation performance. Therefore, we first propose that internal environmental collaboration mediates the effects of AMT adoption on both green product and process innovation.

First, an organization can adopt diverse advanced technologies, while green innovation may not necessarily benefit from such diversity automatically if its internal departments are unwilling to proactively make environmental collaboration. Several researchers have argued that AMT success requires communication and coordination between product and process specialists [20,21]. In other words, investment in AMT is unlikely to be successful without the implementation of internal integration of value-adding functions [8]. Therefore, in order to minimize conflict and successfully deal with the technical and strategic interdependencies inherent in technology adoption, representatives from various departments must carry out cooperation. AMT permits functional integration by linking various functional departments' information systems and common databases [7,9]. Internal 
environmental collaboration, which consists of exchanging technical information, sharing policies, and establishing common goals, can be seen as functional integration that facilitates cooperation among experts, analysts, and decision makers. In terms of developing new skills, fostering trust, and reducing potential resistance, sound and effective coordination is especially important for green innovation [49].

In addition, environmental collaboration focuses more on the means by which more environmentally sound operations or products might be achieved [52]. The proactive environmental management orientation, which requires firms to prevent environmental degradation by an innovative approach to develop environmentally friendly products and processes, is often positively associated with green innovation [53]. By requiring a mutual willingness to learn about each other's operations in order to plan and set goals for environmental improvement [52], internal environmental collaboration leads to more systemic environmental solutions of innovative processes and products by utilizing the AMT. Environmental consciousness of the firm facilitates the redesign of existing products and processes and development of new ones that meet the environmental requirements [54]. Accordingly, the process of implementing AMT can lead to better communication and integration of work across functional boundaries [45] and these changes in interaction may in turn result in better green innovation.

Second, in-depth internal environmental collaboration can detect, employ, and transfer critical technical knowledge across different functions more easily and keep the firm environmentally innovative. Several studies suggest that technical knowledge is one of the most critical factors that must be considered to achieve higher success from AMT implementation [55]. Since technological knowledge is tacit in nature and difficult to be codified and communicated [56], effective internal environmental collaboration among various functions is critical for operators to fully understand and successfully integrate the acquired knowledge.

On the one hand, internal environmental collaboration is an important conduit of inter-firm knowledge transfer. By diffusing, assimilating, communicating, and absorbing the advanced technologies within the organization, internal environmental collaboration facilitates technical knowledge sharing and synchronizes product and process technology development activities. Moreover, internal environmental collaboration through formal and informal mechanisms, including joint planning sessions with regard to the environment and knowledge-sharing activities such as meetings, workshops, and seminars pertaining to management systems [57], enhances a firm's ability to assimilate technological and environmental knowledge. In this way, the acquisition of technological knowledge is complementary and in favor of organizational green innovation [13]. One the other hand, internal environmental collaboration represents a crucial capability of learning. The potential of AMT requires the capacity to learn [32]. By interacting with various departments within the firm, internal environmental collaboration facilitates the uptake of tacit knowledge, especially knowledge pertaining to technical interdependencies between product specifications and manufacturing process specifications to stimulate the generation of new alternatives. Therefore, internal environmental collaboration reflects a key mediator through which AMT contributes to green innovation.

Third, organizations can increase technologies' and resources' productivity through internal environmental collaboration to foster environmental innovation. Environmental collaboration requires an organization to invest specific resources in cooperative activities that address environmental issues [57]. Therefore, internal environmental collaboration is beneficial to potentially capture the added value that emerges from a collaborative interaction of different functions to promote innovation that reduces environmental impact. In addition, through cross-functional cooperation, internal environmental collaboration also facilitates the implementation of product- or process-based modifications and therefore leads to environmental changes in the focal plant's products or processes [58].

In summary, internal environmental collaboration may be the missing link between AMT adoption and green innovation. Hence, we posit that process, design, and planning AMT have potential benefits on a firm's green innovation, and such positive effects are achieved mainly through internal environmental collaboration. 
H3: Internal environmental collaboration mediates the positive effects of the use of (a) process AMT; (b) design AMT; and (c) planning AMT on green product innovation.

H4: Internal environmental collaboration mediates the positive effects of the use of (a) process AMT; (b) design AMT; and (c) planning AMT on green process innovation.

\section{Research Methods}

\subsection{Sampling and Data Collection}

We used the survey method to collect data. Since the AMTs are actually deployed at the manufacturing plant level, manufacturing industries in China were chosen as the research setting. In order to collect data effectively, we strategically selected five typical manufacturing provinces representing different economic development and market formation stages in China, which are Guangdong, Jiangsu, Shandong, Shaanxi, and Henan.

The data collection procedure included three phases. First, an initial English questionnaire was developed based on previous studies and translated into Chinese using two parallel translation/double translations. Two researchers well versed in both languages translated the questionnaire into Chinese and two more back-translated it into English afterwards. The back-translated English version was checked against the original English version for any possible discrepancies. After that, two preliminary assessments of the Chinese survey were implemented. Five manufacturing managers and three academics reviewed the pre-questionnaire to improve clarity and identify and resolve any unfamiliar or unclear wording. Next, eight manufacturing firms were chosen to conduct a pilot test. Based on the feedback, we further modified the questionnaire to ensure it was understandable and relevant to practices in China.

Secondly, we randomly selected 200 firms for each province from a list of firms provided by the local government and business research firms as our sampling frame, totaling 1000 firms. Following the approach of Frohlich [59], selected firms were contacted in advance to identify the key informants. In order to collect reliable data about AMTs, internal environmental collaboration, and green innovation, one person who was familiar with these activities (e.g., the CEO/president, vice president, or senior executive) was chosen as the key informant.

Finally, mail or online surveys, along with a cover letter offering a brief outline of the study and ensuring confidentiality, were sent out to the respondents. We also promised a customized summary report to encourage participation. In addition, both follow-up calls and e-mails were made to increase the response rate.

In total, 212 questionnaires were collected. After deleting responses from missing data, 198 usable questionnaires were obtained, representing an effective response rate of $19.8 \%$. The characteristics of sampled firms are shown in Table 1, indicating a wide variety of industries and sizes.

We employed a multivariate analysis of variance (MANOVA) test to investigate the possible non-response bias [60]. An analysis of differences between early and late responses for all of the variables revealed no statistical significant differences, suggesting non-response bias is not a concern in our study.

Common method bias was a concern as there was only a single respondent for each company [61]. We tried to reduce the potential influence of common method variance (CMV) by carefully selecting scale items and separating them with the fairly lengthy questionnaire [62]. Then we conducted several diagnostic tests to further evaluate the possibility of CMV. First, Harmon's single-factor test was conducted [61]. The results revealed that neither did a single factor emerge, and nor did one general factor explain the majority of the total variance, thus indicating that CMV is not a critical issue.

Secondly, confirmatory factor analysis (CFA) to Harman's single-factor model was conducted [63]. The model's fit indices of $\chi^{2}(299)=3002.81, \mathrm{NNFI}=0.91, \mathrm{CFI}=0.91, \mathrm{RMSEA}=0.214$, and SRMR $=0.085$ were unacceptable and were considerably worse than those of the measurement model. This suggests that a single factor is not acceptable, further indicating that common method bias was not a significant issue. 
Table 1. Profile of sampled firms.

\begin{tabular}{|c|c|c|}
\hline Characteristics of Firms & Frequency & Percentage $(\%)$ \\
\hline \multicolumn{3}{|c|}{ Environmental strategy [64] } \\
\hline \multicolumn{3}{|l|}{ Level of environmental corporate strategy } \\
\hline Lower than industry average & 24 & 12.12 \\
\hline Industry average & 24 & 12.12 \\
\hline Higher than industry average & 150 & 75.76 \\
\hline \multicolumn{3}{|l|}{ Level of environmental marketing strategy } \\
\hline Lower than industry average & 30 & 15.15 \\
\hline Industry average & 16 & 8.08 \\
\hline Higher than industry average & 152 & 76.77 \\
\hline \multicolumn{3}{|l|}{ Industry } \\
\hline Metal products & 19 & 9.6 \\
\hline Machinery and engineering & 21 & 10.61 \\
\hline Electrical machinery and equipment & 25 & 12.63 \\
\hline Communication and computers related equipment & 32 & 16.16 \\
\hline Instruments and related products & 18 & 9.09 \\
\hline others & 83 & 41.92 \\
\hline \multicolumn{3}{|l|}{ Number of employees } \\
\hline Large size (2000 or more) & 34 & 17.17 \\
\hline Medium size (300-2000) & 47 & 23.74 \\
\hline Small size $(<300)$ & 117 & 59.09 \\
\hline \multicolumn{3}{|c|}{ Annual sales (million RMB) } \\
\hline Large size (100 or more) & 60 & 30.3 \\
\hline Medium size (10-100) & 59 & 29.8 \\
\hline Small size $(<10)$ & 79 & 39.9 \\
\hline \multicolumn{3}{|l|}{ Ownership } \\
\hline State-owned & 72 & 36.36 \\
\hline Private-owned & 96 & 48.48 \\
\hline foreign-owned & 30 & 15.15 \\
\hline
\end{tabular}

Note: Environmental corporate strategy refers to the degree to which the natural environment was integrated with the firm's strategic planning processes, as compared to the industry average; Environmental marketing strategy refers to the degree to which the firms' product market decisions were influenced by environmental concerns, as compared to the industry average.

\subsection{Variables and Measures}

The measures of AMT, internal environmental collaboration, and green innovation used in this study were mostly adapted from existing scales found in previous research studies. The indicators were all measured using a seven-point Likert scale: a higher value indicates a higher level of technology implementation and collaboration, or a better performance in the firm's green innovation. The perceptual measurement scales of all constructs are presented in Appendix A.

Independent variable. AMT has been conceptualized as a multidimensional construct in previous studies $[4,7]$. Consistent with these prior studies, we measured the AMT in three categories: process AMT, design AMT, and planning AMT. These three dimensions of AMT are operated as four, five, and four scales, respectively, and measured using the scales adapted from prior work $[7,23]$. Process AMT includes technologies such as CAM and environmental control systems that enable efficient and flexible manufacturing processes. Technologies that aid in the design of products and process such as CAD and PDM are included in design AMT. Planning AMT focuses on planning critical firm resources and covers technologies such as ERP, MRP II, etc. These constructs are assessed by asking the respondents to indicate the extent to which each technology or practice was utilized in their plant for environmental management, as compared to the industry average. 
Dependent variables. We included scales addressing two dimensions of green innovation: green product innovation and green process innovation. To measure green product innovation, respondents were asked to rate various aspects of their new products' performance such as energy saving, pollution prevention, waste recycling, or green product design. The four-item scale was adapted from previous research $[65,66]$. For measures of green process innovation, a four-item scale was adapted from prior studies $[57,67]$ to evaluate managers' perception of how their manufacturing process performed environmentally in terms of decreasing energy, controlling pollution, saving materials, and reducing resources.

Mediating variable. For the measurement of internal environmental collaboration, we employed a five-item scale developed and validated by Vachon and Klassen [52], assessing respondents' perception of the extent to which the relevant function units (i.e., marketing, R\&D, manufacturing, ...) engaged in environmental activities.

Control variables. Prior studies have suggested that the use of AMT and green innovation may be influenced by firm age, size, and ownership [4,49]. Accordingly, we included these control variables in the analysis. Firm age was adopted as the first control variable, which referred to the age of the firm since its foundation. Secondly, we controlled the firm size, which was operated as the natural logarithmic transformation of the number of employees. Finally, we used ownership to control for its possible effects. The firm ownership measure was operationalized as three dummy variables, with state-owned as the baseline.

\subsection{Reliability and Validity}

The reliability of the constructs measured by multiple scales was assessed using Cronbach's coefficient alpha and composite reliability (CR). The Cronbach's alpha values of all constructs ranged from 0.821 to 0.929 , exceeding the generally agreed threshold value of 0.70 [68], which suggested acceptable reliability for all constructs. All CR values were larger than 0.85 , which is higher than the minimum acceptable value of 0.60 , also indicating that all constructs are reliable.

We employed a rigorous process to evaluate the validity of this study. In our study, all the scales used were carefully extracted from existing constructs based on an extensive search of the literature. Moreover, an iterative review of the questionnaire by executives and academicians also helped to improve the items. As such, content validity was established.

We executed a confirmatory factor analysis (CFA) to assess the convergent validity [69]. The results indicate a good fit $\left(\chi^{2}(215)=561.62, \mathrm{NNFI}=0.97, \mathrm{CFI}=0.98, \mathrm{RMSEA}=0.08\right.$ and SRMR $\left.=0.046\right)$ [70] . All factor loadings are significant at the $p<0.001$ level and greater than 0.60 , demonstrating strong convergent validity [71]. Furthermore, the average variance extracted (AVE) values of each construct exceed the 0.50 benchmark [68], suggesting that measures demonstrated adequate convergent validity.

In order to assess the discriminant validity, we compared the calculated share variance between any two constructs against the AVE values of the individual constructs [68]. Table 2 presents the squared correlations between all possible pairs of constructs in the lower left off-diagonal of the matrix and AVE along the diagonal. The results indicated that AVE values were higher than the shared variance with other constructs. Therefore, the discriminant validity was ensured in this study.

Table 2. Discriminant validity test.

\begin{tabular}{ccccccccc}
\hline & Mean & S.D. & PAMT & PLAMT & DAMT & IEC & GPDI & GPCI \\
\hline Process AMT (PAMT) & 5.047 & 1.101 & $\mathbf{0 . 5 9 8}$ & & & & & \\
Design AMT (DAMT) & 4.855 & 1.069 & 0.498 & 0.645 & & & & \\
Planning AMT (PLAMT) & 5.343 & 1.068 & 0.534 & 0.494 & 0.656 & & & \\
Internal environmental collaboration (IEC) & 5.149 & 1.098 & 0.428 & 0.424 & 0.496 & $\mathbf{0 . 8 0 5}$ & & \\
Green product innovation (GPDI) & 5.024 & 1.133 & 0.345 & 0.368 & 0.312 & 0.438 & $\mathbf{0 . 7 6 3}$ & \\
Green process innovation (GPCI) & 5.217 & 1.178 & 0.440 & 0.445 & 0.392 & 0.629 & 0.607 & $\mathbf{0 . 8 2 9}$ \\
\hline
\end{tabular}

Note: Bold numbers on the diagonal show the values of AVE. 


\section{Analysis and Results}

To examine the relationships between sub-dimensions of AMT and green innovation as well as the mediating effects of internal environmental collaboration, a multistep mediated regression approach was adopted [72]. Since two dependent variables are defined in the research model (green product innovation and green process innovation), the regression was run for each of them separately. Table 3 presents the mediating effect of internal environmental collaboration on the link between AMT adoption and green innovation. First, we established the effects of the independent variable (process, planning, and design AMT) on the mediator (internal environmental collaboration) in Model 1. Second, we established that the independent variable affects the dependent variable (green product innovation and green process innovation) in Models 2 and 5. Third, we established the effects of the mediator on the dependent variable in Models 3 and 6. Last, we added both the independent variable and mediator to the regression in Models 4 and 7.

Table 3. Results of regression analysis.

\begin{tabular}{|c|c|c|c|c|c|c|c|}
\hline & \multirow{2}{*}{$\begin{array}{c}\text { IEC } \\
\text { Model } 1\end{array}$} & \multicolumn{3}{|c|}{ GPDI } & \multicolumn{3}{|c|}{ GPCI } \\
\hline & & Model 2 & Model 3 & Model 4 & Model 5 & Model 6 & Model 7 \\
\hline \multicolumn{8}{|c|}{ Control variables } \\
\hline Firm age & $\begin{array}{c}-0.165 \\
(-1.147)\end{array}$ & $\begin{array}{c}0.363 \\
(2.151) *\end{array}$ & $\begin{array}{c}0.515 \\
(3.237)^{* *}\end{array}$ & $\begin{array}{c}0.442 \\
(2.857)^{* *}\end{array}$ & $\begin{array}{c}0.038 \\
(0.235)\end{array}$ & $\begin{array}{c}0.226 \\
(1.651)\end{array}$ & $\begin{array}{c}0.147 \\
(1.121)\end{array}$ \\
\hline Firm size & $\begin{array}{c}-0.101 \\
(-1.249)\end{array}$ & $\begin{array}{c}0.101 \\
(1.063)\end{array}$ & $\begin{array}{c}0.179 \\
(1.994) *\end{array}$ & $\begin{array}{c}0.149 \\
(1.716)^{+}\end{array}$ & $\begin{array}{c}0.070 \\
(0.769)\end{array}$ & $\begin{array}{c}0.168 \\
(2.171)^{*}\end{array}$ & $\begin{array}{c}0.136 \\
(1.850)^{+}\end{array}$ \\
\hline Ownership & $\begin{array}{c}0.184 \\
(1.322)\end{array}$ & $\begin{array}{c}-0.072 \\
(-0.440)\end{array}$ & $\begin{array}{c}-0.238 \\
(-1.583)\end{array}$ & $\begin{array}{c}-0.160 \\
(-1.070)\end{array}$ & $\begin{array}{c}0.152 \\
(0.974)\end{array}$ & $\begin{array}{c}-0.065 \\
(-0.500)\end{array}$ & $\begin{array}{c}0.031 \\
(0.240)\end{array}$ \\
\hline \multicolumn{8}{|c|}{ Main effects } \\
\hline Process AMT & $\begin{array}{c}0.223 \\
(2.664) \text { ** }\end{array}$ & $\begin{array}{c}0.205 \\
(2.089) *\end{array}$ & & $\begin{array}{c}0.098 \\
(1.070)\end{array}$ & $\begin{array}{c}0.313 \\
(3.340)^{* *}\end{array}$ & & $\begin{array}{c}0.166 \\
(2.146) *\end{array}$ \\
\hline Design AMT & $\begin{array}{c}0.430 \\
(5.823)^{* * * *}\end{array}$ & $\begin{array}{c}0.231 \\
(2.668)^{* *}\end{array}$ & & $\begin{array}{c}0.024 \\
(0.281)\end{array}$ & $\begin{array}{c}0.268 \\
(3.242) \text { ** }\end{array}$ & & $\begin{array}{c}-0.016 \\
(-0.215)\end{array}$ \\
\hline Planning AMT & $\begin{array}{c}0.195 \\
(2.294) *\end{array}$ & $\begin{array}{c}0.308 \\
(3.090)^{* *}\end{array}$ & & $\begin{array}{c}0.214 \\
(2.319) *\end{array}$ & $\begin{array}{c}0.297 \\
(3.110)\end{array}$ & & $\begin{array}{c}0.168 \\
(2.141)^{*}\end{array}$ \\
\hline \multicolumn{8}{|c|}{ Mediation } \\
\hline IEC & & & $\begin{array}{c}0.697 \\
(13.089)^{* * *}\end{array}$ & $\begin{array}{c}0.480 \\
(6.200)^{* * *}\end{array}$ & & $\begin{array}{c}0.865 \\
(18.855)^{* * *}\end{array}$ & $\begin{array}{c}0.661 \\
(10.054)^{* * *}\end{array}$ \\
\hline$R^{2}$ & 0.568 & 0.444 & 0.494 & 0.538 & 0.528 & 0.652 & 0.692 \\
\hline Adjusted $R^{2}$ & 0.554 & 0.427 & 0.483 & 0.521 & 0.514 & 0.645 & 0.681 \\
\hline$F$-value & $41.842^{* * *}$ & $25.468^{* * *}$ & $47.015^{* * *}$ & $31.598^{* * *}$ & $35.672 * * *$ & $90.341^{* * *}$ & $61.035^{* * *}$ \\
\hline
\end{tabular}

In terms of support for H1, the results of Model 2 show that the use of process, design, and planning AMT all have significant positive effects on green product innovation $(p<0.05, p<0.01$, and $p<0.01$, respectively). Thus $\mathrm{H} 1 \mathrm{a}, \mathrm{H} 1 \mathrm{~b}$, and $\mathrm{H} 1 \mathrm{c}$ are strongly supported. These findings are consistent with the notion that the adoption of AMT has a critical positive association with green product innovation.

In terms of support for $\mathrm{H} 2$, the results of Model 5 show that the use of process, design, and planning AMT has a significant positive effect on green process innovation $(p<0.01)$. H2a, H2b, and $\mathrm{H} 2 \mathrm{c}$ are confirmed and supported. These findings support the claim that the three types of AMT all have great potential benefits for green process innovation.

For mediating effects, the results of Model 1 show that the effects of process, design, and planning AMT on internal environmental collaboration are positive and significant $(p<0.01, p<0.001$, 
and $p<0.05$, respectively). The results of Models 3 and 6 demonstrate that internal environmental collaboration significantly affects green product and process innovation $(p<0.001)$.

The results of Model 4 show that, when internal environmental collaboration was added to the regression model, the effects of process AMT and design AMT become insignificant $(p>0.10)$, indicating that internal environmental collaboration completely mediates the positive effects of process and design AMT on green product innovation. $\mathrm{H} 3 \mathrm{a}$ and $\mathrm{H} 3 \mathrm{~b}$ are strongly supported. Moreover, the effect of planning AMT becomes smaller (from 0.308 to 0.214 ) and less significant (from $p<0.01$ to $p<0.05$ ) compared with Model 2, thus the partial mediation effect of internal environmental collaboration is established to partially support H3c. These results indicate that process and design AMT enhance green product innovation, mainly indirectly through internal environmental collaboration, while planning AMT fosters green product innovation both directly and indirectly through internal environmental collaboration.

The results of Model 7 show that, after internal environmental collaboration was controlled for, the effects of process and planning AMT become smaller (from 0.313 to 0.166 and from 0.297 to 0.168 , respectively) and less significant (from $p<0.01$ to $p<0.05$, respectively). Thus, the partial mediation effect of internal environmental collaboration is established to support H4a and H4c. In addition, the effects of design AMT become insignificant $(p>0.10)$ compared with Model 5 , indicating that internal environmental collaboration completely mediates the positive effects of design AMT on green process innovation. H4b is thus strongly supported. These results indicate that process and planning AMT fosters green product innovation both directly and indirectly through internal environmental collaboration, while the positive impact of design AMT on green process innovation is exerted indirectly through internal environmental collaboration.

\section{Discussion and Managerial Implications}

\subsection{Discussion}

This study empirically examines whether and how three fundamental types of AMT impact on two dimensions of green innovation as well as the mediating effect of internal environmental collaboration. We find that the benefits of AMT adoption for green innovation are manifested in the critical capability of internal environmental collaboration. These findings provide important insights for manufacturing firms to foster their green innovation through implementing AMT more effectively.

Considering the three types of AMT, our research findings show that the use of AMT has a positive effect on green innovation. As we expected, the use of process, design, and planning AMT exerts positive effects on the generation of both green products and processes. These findings indicate that all three types of AMT are important drivers to improve green innovation. The significant main effects of AMT adoption on green innovation uncovered in our analysis confirm arguments put forward in prior studies [12]. The use of AMT is often heralded as a technological answer to increase competitiveness and enhance innovation [13]. The adoption of process, design, and planning AMT provide firms with important sources of technological knowledge and enhances the competence of a firm to recombine technological knowledge in creative ways [38]. New technological knowledge creates new opportunities for firms to perform green innovation activities. Moreover, the use of AMT also represents a learning process [19] that helps manufacturing firms to innovate better. In addition, the implementation of AMT also automates the collection, transfer, and sharing of critical information related to green innovation. AMT's information processing capabilities enable greater problem solving and thereby lead to improved green product and process innovation. Therefore, the use of AMT has a positive effect on green innovation. This study adds to the literature by offering a more fine-grained empirical analysis and revealing the great importance that the use of process, design, and planning AMT has for enhancing green products and process innovation in manufacturing firms.

Moreover, in accordance with our expectations, internal environmental collaboration appears to be a critical mediator in achieving AMT's potential benefit on green innovation. Specifically, internal environmental collaboration completely mediates the positive effects of process AMT on 
green product innovation as well as the effects of design AMT on two dimensions of green innovation. These findings indicate that process AMT fosters green product innovation mainly through enhancing internal environmental collaboration. Meanwhile, the positive impacts of design AMT on both green product and process innovation are exerted mainly indirectly through internal environmental collaboration. In addition, we find that internal environmental collaboration partially mediates the effect of process AMT on green process innovation as well as the effects of planning AMT on two dimensions of green innovation. These findings suggest that process AMT enhances green process innovation both directly and indirectly through internal environmental collaboration. Similar, planning AMT fosters green product and process innovation both directly and indirectly through internal environmental collaboration.

Importantly, our findings indicate that both green product and process innovation may not necessarily benefit from the various types of AMT adoption automatically without internal departments being willing to collaborate. The application of process, design, and planning AMT provides firms with access to rich technological knowledge; however, its potential value can only be achieved if representatives of various departments can cooperate to innovate. Internal environmental collaboration addresses interdependencies and information sharing among knowledge workers [73]. In the same way that internal environmental collaboration uncovers technical dependencies between product design and machine processing requirements, internal environmental collaboration also serves to clarify the impacts on production flows that result from product complexity and variety. Thus, internal environmental collaboration helps designers better understand AMT capabilities and limitations, which leads to better applications of technology, and a better fit between product and process designs and environmental requirements [16].

The findings highlight the critical mediating role of internal environmental collaboration in the relationship between AMT and green innovation. To this end, this study addressed the need for an empirical study examining the underlying mechanisms of how AMT adoption enhances green innovation. The findings serve as a useful extension of AMT and green innovation literature by assuring that when firms are interested in adopting AMT and fostering green innovation, it is vital to understand the underlying process between them.

\subsection{Managerial Implications}

The findings of this study provide important implications for firms to more effectively carry out AMT to foster green innovation. First, the findings suggest that managers of firms seeking to strengthen green innovation should direct more attention to AMT adoption. Through implementing the various types of AMT, firms can gain diversified technological resources and critical knowledge that generally improve green product and process innovation. Therefore, managers should proactively employ AMT in firms since it appears to be a good investment. However, the use of AMT is not free; managers should strike a balance and find an optimal level of AMT adoption. Meanwhile, managers who plan to use AMT should carefully consider the dimensions of green innovation they are seeking, as well as their links to the overall manufacturing strategy.

Secondly, the findings suggest that it is important for managers to be aware of the crucial mediating effect of internal environmental collaboration since merely developing AMT is not sufficient for enhancing green innovation. Both green product and process innovation are achieved through internal environmental collaboration. A comprehensive understanding of the vital mediating role of internal environmental collaboration may make firms rethink their AMT implementation activities. Firms' failure to understand the mediating role of internal environmental collaboration may be unable to reap the maximum benefits from AMT adoption and will be in danger of missing out on future opportunities. Therefore, in order to reinforce green innovation through implementing AMT, managers should begin by promoting internal environmental collaboration. By proactively implementing policies and practices to enhance internal environmental collaboration, managers could maximize the effectiveness of AMT adoption. 
In addition, our findings are particularly useful for managers of Chinese manufacturers, who need to improve their green innovation by using different types of AMT. Environmental degradation has been a critical issue in China. For instance, the high level of average annual growth in GDP is also the cause of a high rate of resource consumption and pollutant generation [74-76]. Thus, managers of Chinese manufacturing firms face a serious situation and need to make more efforts to be green.

\section{Conclusions and Limitations}

\subsection{Research Contributions}

This study provides several important contributions to the existing research on green innovation. First, it adds to the literature by incorporating AMT as a potential antecedent and empirically testing the relationships between particular types of AMT and specific dimensions of green innovation, thereby addressing the critical research question of how AMT usage can contribute to green innovation. Previous studies aimed at emphasizing the benefits of AMT on innovation, but empirical analysis has not typically investigated the importance of using AMT for green innovation [12]. In including process, design, and planning AMT, and incorporating both green product and green process innovation, this study enriches the existing green innovation literature and enhances our understanding of the value of AMT adoption for boosting green innovation.

Secondly, this study provides a greater level of comprehensiveness and richness to the AMT-green innovation framework by developing a theoretical model of how firms' green innovation benefits from the uses of AMT through the critical mediator of internal environmental collaboration. Although researchers have recognized the importance of AMT adoption in achieving innovation [12,13], few studies have examined the underlying mechanism by which AMT can contribute to green innovation. Through introducing internal environmental collaboration as an important mediator, our findings suggest that the use of various types of AMT improves green product and process innovation mainly through enhancing internal environmental collaboration, which provides preliminary evidence that organizational capabilities such as internal environmental collaboration act as a critical mediator for firms' green innovation to benefit from the use of AMT.

Thirdly, this study extends the AMT and green innovation literature into the context of China. Previous related studies were typically carried out in other contexts, such as the USA [4], Australia, Britain, Canada [21], and Russia [13]. China, the largest global manufacturing center, is experiencing an important period of economic transformation. Since the formal institutional market system and infrastructures that support innovation have not yet been well established, Chinese firms have a greater incentive to gain competitive advantages and be more innovative [77]. Effective uses of AMT have potential benefits on green product and process innovation. Chinese manufacturers can maximize these benefits through enhancing internal environmental collaboration.

\subsection{Limitations and Future Research}

While this study makes a significant contribution to the literature and has important implications for practice, it has several limitations that provide useful opportunities for further research. First, this study uses a cross-sectional design to investigate the relationship between uses of AMT, internal environmental collaboration, and green innovation. The survey data may cast doubt on causal statements derived from empirical findings. Therefore, a further potentially fruitful area for future research would be examining the evolution of AMT usage in a longitudinal experimental design.

Secondly, a key limitation stems from the reliance on a single informant to represent each firm in the sample. The positions of the respondents, as well as procedures taken in data collection and analyses, argue against serious effects of bias and common method variance. Future studies could benefit from using multiple respondents to further substantiate our finding of a relationship between AMT practice and green innovation. 
Thirdly, our findings reveal that internal environmental collaboration has a critical mediating effect on the relationship between the use of AMT and green innovation. We did not address other potential mediators, such as technology absorptive capacity, and cross-functional integration. We leave it for future research to further substantiate our findings, as well as to develop an even more comprehensive theory of AMT adoption and green innovation.

Finally, the Chinese context of this study may limit the generalizability of the findings. China has a specific culture of Confucianism, a history of development, and an institutional environment. Its unique traits suggest that the behavior of manufacturing firms in China may differ from that of other countries or developed economies. Future research should investigate the proposed relationships in other countries or developed economies.

Acknowledgments: This work was supported by the National Natural Science Foundation of China (71271138), and the Fundamental Research Funds for the Central Universities (3102016RW003).

Author Contributions: Taiwen Feng conceived and designed the experiments; Ting Kong performed the experiments and analyzed the data; Chunming Ye contributed reagents/materials/analysis tools; Ting Kong and Taiwen Feng wrote the paper.

Conflicts of Interest: The authors declare no conflict of interest.

\section{Appendix A}

Table A1. Survey instrument (with factor loadings).

\begin{tabular}{|c|c|}
\hline Item & Loading \\
\hline \multicolumn{2}{|l|}{ Process AMT $(\alpha=0.821)$} \\
\hline PAMT1: Computer-aided manufacturing (CAM) technology practice is applied. & 0.711 \\
\hline PAMT2: Robotics is used. & 0.874 \\
\hline PAMT3: Flexible manufacturing systems (FMS) technology practice is applied. & 0.727 \\
\hline PAMT4: Environmental control systems are applied. & 0.770 \\
\hline \multicolumn{2}{|l|}{ Design AMT $(\alpha=0.874)$} \\
\hline DAMT1: Computer-aided process planning (CAPP) technology practice is applied. & 0.831 \\
\hline DAMT2: Computer-aided design (CAD) technology practice is applied. & 0.905 \\
\hline DAMT3: Product data management (PDM) systems are used. & - \\
\hline DAMT4: Computer-aided engineering (CAE) technology practice is applied. & 0.719 \\
\hline DAMT5: Rapid prototyping (e.g., stereolithography) technology practice is applied. & 0.754 \\
\hline \multicolumn{2}{|l|}{ Planning AMT $(\alpha=0.881)$} \\
\hline PAMT1: Enterprise resource planning system (ERP) is used. & 0.871 \\
\hline PAMT2: Advanced MRP II system is used. & 0.767 \\
\hline PAMT3: Activity-based accounting $(A B C)$ is used. & 0.800 \\
\hline PAMT4: Decision support systems (DSS) are applied. & 0.798 \\
\hline \multicolumn{2}{|l|}{ Internal environmental collaboration $(\alpha=0.927)$} \\
\hline IEC1: Achieving environmental goals collectively. & - \\
\hline IEC2: Developing a mutual understanding of responsibilities regarding environmental performance. & 0.908 \\
\hline IEC3: Working together to reduce the environmental impact of our activities. & 0.895 \\
\hline IEC4: Conducting joint planning to anticipate and resolve environment-related problems. & 0.931 \\
\hline IEC5: Making joint decisions about ways to reduce the environmental impact of our products/services. & 0.854 \\
\hline \multicolumn{2}{|l|}{ Green product innovation $(\alpha=0.929)$} \\
\hline GPDI1: The new products reduce the consumption of materials/energy. & 0.777 \\
\hline GPDI2: The new products reuse, recycle, and recover materials and component parts. & 0.887 \\
\hline GPDI3: The new products reduce resource consumption and waste generation in product usage. & 0.920 \\
\hline GPDI4: The new products reduce the environmental impact of product disposal. & 0.902 \\
\hline \multicolumn{2}{|l|}{ Green process innovation $(\alpha=0.919)$} \\
\hline GPCI1: The manufacturing process uses clean technology/equipment. & - \\
\hline GPCI2: The manufacturing process installs energy-efficient equipment. & 0.915 \\
\hline GPCI3: The manufacturing process installs pollution control technologies. & 0.943 \\
\hline $\begin{array}{l}\text { GPCI4: Production planning and control during the manufacturing process focused on reducing waste } \\
\text { and optimizing materials. }\end{array}$ & 0.872 \\
\hline
\end{tabular}

Note: Three items (DAMT3, IEC1, and GPCI1) were deleted after reliability or validity analysis. 


\section{References}

1. Porter, M.E.; Linde, C.V.D. Green and competitive: Ending the stalemate. Harv. Bus. Rev. 1995, 73, $128-129$.

2. Sharma, S. Managerial Interpretations and Organizational Context as Predictors of Corporate Choice of Environmental Strategy. Acad. Manag. J. 2000, 43, 681-697. [CrossRef]

3. Schiederig, T.; Tietze, F.; Herstatt, C. Green innovation in technology and innovation management-An exploratory literature review. RD Manag. 2012, 42, 180-192. [CrossRef]

4. Swink, M.; Nair, A. Capturing the competitive advantages of AMT: Design-manufacturing integration as a complementary asset. J. Oper. Manag. 2007, 25, 736-754. [CrossRef]

5. Kotha, S.; Swamidass, P.M. Strategy, advanced manufacturing technology and performance: Empirical evidence from US manufacturing firms. J. Oper. Manag. 2000, 18, 257-277. [CrossRef]

6. Wemmerlöv, U.; Hyer, N.L. Cellular manufacturing in the U.S. industry: A survey of users. Int. J. Prod. Res. 1989, 27, 1511-1530. [CrossRef]

7. Swamidass, P.M.; Kotha, S. Explaining manufacturing technology use, firm size and performance using a multidimensional view of technology. J. Oper. Manag. 1998, 17, 23-37. [CrossRef]

8. Lei, D.; Hitt, M.A.; Goldhar, J.D. Advanced Manufacturing Technology: Organizational Design and Strategic Flexibility. Organ. Stud. 1996, 17, 501-523. [CrossRef]

9. Tracey, M.; Vonderembse, M.A.; Lim, J.S. Manufacturing technology and strategy formulation: Keys to enhancing competitiveness and improving performance. J. Oper. Manag. 1999, 17, 411-428. [CrossRef]

10. Hofmann, C.; Orr, S. Advanced manufacturing technology adoption-The German experience. Technovation 2005, 25, 711-724. [CrossRef]

11. Cagliano, R.; Spina, G. Advanced manufacturing technologies and strategically flexible production. J. Oper. Manag. 2000, 18, 169-190. [CrossRef]

12. Santamaría, L.; Nieto, M.J.; Barge-Gil, A. Beyond formal R\&D: Taking advantage of other sources of innovation in low-and medium-technology industries. Res. Policy 2009, 38, 507-517.

13. Trifilova, A.; Bartlett, D. Green technology and eco-innovation: Seven case-Studies from a Russian manufacturing context. J. Manuf. Technol. Manag. 2010, 21, 910-929.

14. Small, M.H.; Yasin, M.M. Advanced manufacturing technology: Implementation policy and performance. J. Oper. Manag. 1997, 15, 349-370. [CrossRef]

15. Nair, A.; Swink, M. Linking internal process technology development and the use of AMT with manufacturing plant performance-An examination of complementarities and redundancies. IEEE Trans. Eng. Manag. 2007, 54, 742-755. [CrossRef]

16. Klassen, R.D.; Whybark, D.C. Environmental Management in Operations: The Selection of Environmental Technologies. Decision Sci. 1999, 30, 601-631. [CrossRef]

17. Tseng, M.L.; Wang, R.; Chiu, A.S.F.; Geng, Y.; Lin, Y.H. Improving performance of green innovation practices under uncertainty. J. Clean. Prod. 2013, 40,71-82. [CrossRef]

18. Weng, H.H.; Chen, J.S.; Chen, P.C. Effects of Green Innovation on Environmental and Corporate Performance: A Stakeholder Perspective. Sustainability 2015, 7, 209-214. [CrossRef]

19. Sohal, A.; Sarros, J.; Schroder, R.; O'neill, P. Adoption framework for advanced manufacturing technologies. Int. J. Prod. Res. 2006, 44, 5225-5246. [CrossRef]

20. Udo, G.J.; Ehie, I.C. Advanced manufacturing technologies: Determinants of implementation success. Int. J. Oper. Prod. Manag. 1996, 16, 6-26. [CrossRef]

21. Burcher, P.; Lee, G.; Sohal, A. Lessons for implementing AMT: Some case experiences with CNC in Australia, Britain and Canada. Int. J. Oper. Prod. Manag. 1999, 19, 515-527. [CrossRef]

22. Das, A.; Jayaram, J. Relative importance of contingency variables for advanced manufacturing technology. Int. J. Prod. Res. 2003, 41, 4429-4452. [CrossRef]

23. Boyer, K.K.; Leong, G.K.; Ward, P.T.; Krajewski, L.J. Unlocking the potential of advanced manufacturing technologies. J. Oper. Manag. 1997, 15, 331-347. [CrossRef]

24. Zhang, Q.; Vonderembse, M.A.; Cao, M. Achieving flexible manufacturing competence: The roles of advanced manufacturing technology and operations improvement practices. Int. J. Oper. Prod. Manag. 2006, 26, 580-599. [CrossRef]

25. Chen, Y.S.; Lai, S.B.; Wen, C.T. The influence of green innovation performance on corporate advantage in Taiwan. J. Bus. Ethics 2006, 67, 331-339. [CrossRef] 
26. Chen, Y.S. The driver of green innovation and green image - green core competence. J. Bus. Ethics 2008, 81, 531-543. [CrossRef]

27. Orsato, R.J. Competitive Environmental Strategies: When does it pay to be green? Calif. Manag. Rev. 2006, 48, 127-143. [CrossRef]

28. Barney, J. Firm resources and sustained competitive advantage. J. Manag. 1991, 17, 99-120. [CrossRef]

29. Wagner, H.T.; Morton, S.C.; Dainty, A.R.J.; Burns, N.D. Path dependent constraints on innovation programmes in production and operations management. Int. J. Prod. Res. 2011, 49, 3069-3085. [CrossRef]

30. Cooper, R.G.; Kleinschmidt, E.J. New products: What separates winners from losers? J. Prod. Innov. Manag. 1987, 4, 169-184. [CrossRef]

31. Kumar, V.; Murphy, S.A.; Loo, S.C.K. An investment decision process: The case of advanced manufacturing technologies in Canadian manufacturing firms. Int. J. Prod. Res. 1996, 34, 947-958. [CrossRef]

32. Khazanchi, S.; Lewis, M.W.; Boyer, K.K. Innovation-supportive culture: The impact of organizational values on process innovation. J. Oper. Manag. 2007, 25, 871-884. [CrossRef]

33. Subramaniam, M.; Youndt, M.A. The Influence of Intellectual Capital on the Types of Innovative Capabilities. Acad. Manag. J. 2005, 48, 450-463. [CrossRef]

34. Cohen, W.M.; Levinthal, D.A. Absorptive Capacity: A New Perspective on Learning and Innovation. Admin. Sci. Quart. 1990, 35, 128-152. [CrossRef]

35. Piening, E.P.; Salge, T.O. Understanding the Antecedents, Contingencies, and Performance Implications of Process Innovation: A Dynamic Capabilities Perspective. J. Prod. Innov. Manag. 2015, 32, 80-97. [CrossRef]

36. Noci, G.; Verganti, R. Managing 'green' product innovation in small firms. R D Manag. 1998, $29,3-15$.

37. Moyanofuentes, J.; Sacristándíaz, M.; Garridovega, P. Improving supply chain responsiveness through Advanced Manufacturing Technology: The mediating role of internal and external integration. Prod. Plan. Control 2016, 27, 686-697. [CrossRef]

38. Kogut, B.; Zander, U. Knowledge of the Firm, Combinative Capabilities, and the Replication of Technology. Organ. Sci. 1992, 3, 17-35. [CrossRef]

39. Chen, C.J.; Huang, J.W. Strategic human resource practices and innovation performance-The mediating role of knowledge management capacity. J. Bus. Res. 2009, 62, 104-114. [CrossRef]

40. Rodan, S.; Galunic, C. More than network structure: How knowledge heterogeneity influences managerial performance and innovativeness. Strateg. Manag. J. 2004, 25, 541-562. [CrossRef]

41. Fleming, L. Recombinant Uncertainty in Technological Search. Manag. Sci. 2001, 47, 117-132. [CrossRef]

42. Chen, Y.S.; Lin, Y.H.; Lin, C.Y.; Chang, C.W. Enhancing Green Absorptive Capacity, Green Dynamic Capacities and Green Service Innovation to Improve Firm Performance: An Analysis of Structural Equation Modeling (SEM). Sustainability 2015, 7, 15674-15692. [CrossRef]

43. Berkel, R.V. Eco-Innovation: Opportunities for advancing waste prevention. Int. J. Environ. Technol. Manag. 2007, 7, 527-550. [CrossRef]

44. Machiba, T. Eco-innovation for enabling resource efficiency and green growth: Development of an analytical framework and preliminary analysis of industry and policy practices. Int. Econ. Econ. Policy 2010, 7, 357-370. [CrossRef]

45. Zairi, M. Measuring success in AMT implementation using customer-supplier interaction criteria. Int. J. Oper. Prod. Manag. 1992, 12, 34-55. [CrossRef]

46. Turkulainen, V.; Ketokivi, M. Cross-functional integration and performance: What are the real benefits? Int. J. Oper. Prod. Mang. 2012, 32, 447-467. [CrossRef]

47. Lewis, M.W.; Boyer, K.K. Factors impacting AMT implementation: An integrative and controlled study. J. Eng. Technol. Manag. 2002, 19, 111-130. [CrossRef]

48. Zammuto, R.F.; O'Connor, E.J. Gaining advanced manufacutring technologies' benifits: The roles of organization design and culture. Acad. Manag. Rev. 1992, 17, 701-728.

49. Horbach, J. Determinants of environmental innovation-New evidence from German panel data sources. Res. Policy 2008, 37, 163-173. [CrossRef]

50. Adler, P.S. CAD/CAM: Managerial challenges and research issues. IEEE Trans. Eng. Manag. 1989, 36, 202-215. [CrossRef]

51. Hart, S.L. A natural resource-based view of the firm. Acad. Manag. Rev. 1995, 20, 986-1014.

52. Vachon, S.; Klassen, R.D. Environmental management and manufacturing performance: The role of collaboration in the supply chain. Int. J. Prod. Econ. 2008, 111, 299-315. [CrossRef] 
53. Ryszko, A. Proactive Environmental Strategy, Technological Eco-Innovation and Firm Performance-Case of Poland. Sustainability 2016, 8, 156. [CrossRef]

54. Ram, N.; Prahalad, C.K.; Rangaswami, M.R. Why sustainbility is now the key driver of innovation. Harv. Bus. Rev. 2009, 87, 57-64.

55. Zhao, H.; Co, H.C. Adoption and implementation of advanced manufacturing technology in Singapore. Int. J. Prod. Econ. 1997, 48, 7-19. [CrossRef]

56. Li, J.J.; Poppo, L.; Zhou, K.Z. Relational mechanisms, formal contracts, and local knowledge acquisition by international subsidiaries. Strateg. Manag. J. 2010, 31, 349-370. [CrossRef]

57. Vachon, S. Green supply chain practices and the selection of environmental technologies. Int. J. Prod. Res. 2007, 45, 4357-4379. [CrossRef]

58. Geffen, C.A.; Rothenberg, S. Suppliers and environmental innovation: The automotive paint process. Int. J. Oper. Prod. Manag. 2000, 20, 166-186. [CrossRef]

59. Frohlich, M.T. Techniques for improving response rates in OM survey research. J. Oper. Manag. 2002, 20, 53-62. [CrossRef]

60. Armstrong, J.; Overton, T. Estimating nonresponse bias in mail surveys. J. Mark. Res. 1977, 14, 396-402. [CrossRef]

61. Podsakoff, P.M.; MacKenzie, S.B.; Lee, J.Y.; Podsakoff, N.P. Common method biases in behavioral research: A critical review of the literature and recommended remedies. J. Appl. Psychol. 2003, 88, 879-903. [CrossRef] [PubMed]

62. Podsakoff, P.M.; Organ, D.W. Self-reports in organizational research: Problems and prospects. J. Manag. 1986, 12, 531-544. [CrossRef]

63. Sanchez, J.I.; Brock, P. Outcomes of perceived discrimination among hispanic employees: Is diversity management a luxury or a necessity? Acad. Manag. J. 1996, 39, 704-719. [CrossRef]

64. Banerjee, S.B.; Kashyap, R.K. Corporate Environmentalism: Antecedents and Influence of Industry Type. J. Mark. 2003, 67, 106-122. [CrossRef]

65. Prajogo, D.; Tang, A.K.Y.; Lai, K.-H. The diffusion of environmental management system and its effect on environmental management practices. Int. J. Oper. Prod. Manag. 2014, 34, 565-585. [CrossRef]

66. Zhu, Q.; Sarkis, J.; Lai, K.-H. Confirmation of a measurement model for green supply chain management practices implementation. Int. J. Prod. Econ. 2008, 111, 261-273. [CrossRef]

67. Sroufe, R. Effects of environmental management systems on environmental management practices and operations. Prod. Oper. Manag. 2003, 12, 416-431. [CrossRef]

68. Fornell, C.; Larcker, D.F. Evaluating structural equation models with unobservable variables and measurement error. J. Mark. Res. 1981, 18, 39-50. [CrossRef]

69. O’Leary-Kelly, S.W.; Vokurka, R.J. The empirical assessment of construct validity. J. Oper. Manag. 1998, 16, 387-405. [CrossRef]

70. Hu, L.-T.; Bentler, P.M. Cutoff criteria for fit indexes in covariance structure analysis: Conventional criteria versus new alternatives. Struct. Equ. Model. 1999, 6, 1-55. [CrossRef]

71. Anderson, J.C. An approach for confirmatory measurement and structural equation modeling of organizational properties. Manag. Sci. 1987, 33, 525-541. [CrossRef]

72. Baron, R.M.; Kenny, D.A. The moderator-mediator variable distinction in social psychological research: Conceptual, strategic, and statistical considerations. J. Pers. Soc. Psychol. 1986, 51, 1173-1182. [CrossRef] [PubMed]

73. Adler, P.S. Interdepartmental interdependence and coordination: The case of the design/manufacturing interface. Organ. Sci. 1995, 6, 147-167. [CrossRef]

74. Zhang, K.M.; Wen, Z.G. Review and challenges of policies of environmental protection and sustainable development in China. J. Environ. Manag. 2008, 88, 1249-1261. [CrossRef] [PubMed]

75. Feng, T.; Wang, D. The influence of environmental management systems on financial performance: A moderated-mediation analysis. J. Bus. Ethics 2016, 135, 265-278. [CrossRef]

76. Feng, T.; Cai, D.; Wang, D.; Zhang, X. Environmental management systems and financial performance: The joint effect of switching cost and competitive intensity. J. Clean. Prod. 2016, 113, 781-791. [CrossRef]

77. Peng, M.W.; Heath, P.S. The growth of the firm in planned economies in transition: Institutions, organizations, and strategic choice. Acad. Manag. Rev. 1996, 21, 492-528.

(C) 2016 by the authors; licensee MDPI, Basel, Switzerland. This article is an open access article distributed under the terms and conditions of the Creative Commons Attribution (CC-BY) license (http://creativecommons.org/licenses/by/4.0/). 